\title{
Functional characterization of the DNA mismatch binding protein MutS from Haemophilus influenzae
}

\author{
Nimesh Joseph, Viswanadham Duppatla, Desirazu N. Rao* \\ Department of Biochemistry, Indian Institute of Science, Bangalore 560 012, India
}

\begin{abstract}
This investigation demonstrates DNA mismatch repair activity in Haemophilus influenzae cell free extracts. The mutS gene as well as purified protein of $H$. influenzae restored repair activity in complementation assays performed with mut $S$ deficient Escherichia coli strain. The difference in affinity for GT and AC mismatched bases by $H$. influenzae MutS was reflected in the efficiency with which these DNA heteroduplexes were repaired in vitro, with GT being repaired well and AC the least. Unlike $E$. coli MutS, the $H$. influenzae homolog failed to give protein-DNA complex with homoduplex DNA. Interestingly, MutS was found to bind single-stranded DNA but with lesser affinity as compared to heteroduplex DNA. Apart from the nucleotide- and DNA-mediated conformational transitions, as monitored by circular dichroism and limited proteolysis, our data suggest a functional role when $H$. influenzae MutS encounters single-stranded DNA during exonucleolytic step of DNA repair process. We propose that, conformational changes in H. influenzae MutS not only modulate mismatch recognition but also trigger some of the down stream processes involved in the DNA mismatch repair process.
\end{abstract}

Keywords: Haemophilus influenzae; DNA mismatch repair; MutS; ATPase; DNA binding; Limited proteolysis; Electrophoretic mobility shift; In vivo complementation; In vitro complementation; Circular dichroism; Heteroduplex DNA

One of the most extensively studied prokaryotic mismatch repair systems is the methyl-directed mismatch repair pathway of Escherichia coli. The methyl-directed mismatch repair pathway of $E$. coli has been reconstituted in vitro using purified components and has been shown to require nearly 11 proteins, MutS, MutL, MutH, DNA helicase II, SSB, Rec J, exonuclease I, exonuclease VII, exonuclease X, DNA polymerase III holoenzyme, and DNA ligase [13,30]. The methyl-directed mismatch repair system processes base pairing errors within the helix in a strand-specific manner by exploiting patterns of DNA methylation [2]. Repair is initiated by the binding of MutS to the mismatched base $[34,40]$ followed by its recruitment of MutL, the entire process being regulated by ATP [19]. Assembly of this ternary

\footnotetext{
* Corresponding author. Fax: +91 $8023600683 / 918023600814$.

E-mail address: dnrao@biochem.iisc.ernet.in (D.N. Rao).
}

complex is adequate to activate the nicking endonuclease activity of MutH, which incises the unmethylated strand at a hemimethylated d(GATC) sequence [43]. The unwinding activity of DNA helicase II (uvrD/mutU gene product) is also initiated at the incised d(GATC) sequence and unwinds DNA towards the mismatched base [15]. The resultant single-stranded DNA is subjected to degradation by one of the several single-strand DNA exonucleases $[14,20]$. DNA removed in this manner is resynthesized by DNA polymerase III holoenzyme in the presence of single-strand DNA-binding protein. Eventually, DNA ligase restores covalent continuity to the repaired strand [30]. Mutant strains defective in mut $H$, mutL, mutS or uvrD are spontaneous mutators and are deficient in mismatch correction [34].

Haemophilus influenzae is a naturally transformable gram-negative bacterium. It is widespread in its distribution among the human population and is commonly 
seen as a secondary invader after the infection by influenza virus. The pathogenic potential of $H$. influenzae critically depends on the phenomenon of phase variation of a number of surface-expressed molecules [24]. Monoand dinucleotide repeat tracts produce large numbers of slippage events that are corrected by the mismatch repair pathway. Inactivation of mutS in $H$. influenzae was found to destabilize dinucleotide repeat tracts of chromosomally located reporter constructs implicating mismatch repair pathway in generating phase variation [4]. Watson et al. [42] recently reported hypermutable mut $S$ mutants of $H$. influenzae in the sputum of cystic fibrosis patients.

Sequencing of the complete genome of $H$. influenzae $\mathrm{Rd}$ revealed the existence of the homologs of $E$. coli DNA mismatch repair genes [16], i.e., mutH, mutL, and $m u t S$. Though the mutH and mutL gene products of $H$. influenzae are functionally characterized, [17,25] the mutS homolog has not been studied in detail so far. It was, therefore envisaged that a comprehensive analysis of the newly obtained MutS from $H$. influenzae could potentially consolidate and even advance our knowledge about MutS and its role in DNA mismatch repair.

\section{Materials and methods}

Growth of E. coli and H. influenzae strains. Escherichia coli strains used for the preparation of cell free extracts for the mismatch repair assays were grown at $37^{\circ} \mathrm{C}$ in LB broth supplemented with $0.1 \%$ glucose until late-exponential phase $\left(\mathrm{OD}_{600}\right.$ approximately $\left.1.0-1.2\right)$. BL21(DE3) pLysS strain transformed with the mutS gene construct in pET15b was grown in LB broth supplemented with $100 \mu \mathrm{g} / \mathrm{ml}$ ampicillin. H. influenzae $\mathrm{Rd}(\mathrm{KW} 20)$ strain was grown at $37^{\circ} \mathrm{C}$ in brain heart infusion (BHI) broth supplemented with hemin $(10 \mu \mathrm{g} / \mathrm{ml})$ and $\beta-\mathrm{NAD}^{+}(10 \mu \mathrm{g} / \mathrm{ml})$ until late-exponential phase $\left(\mathrm{OD}_{600}\right.$ approximately 1.0-1.2), which was used for the preparation of cell free extract.

Substrate for in vitro mismatch repair assay. The substrate for in vitro mismatch correction is a 6440-bp, covalently closed circular DNA or with a single nick on the unmethylated strand, derived from the bacteriophage f1 and contains a GT base-base mismatch located within the overlapping recognition sites for two restriction endonucleases, HindIII and XhoI, at position 5632. Although the presence of mispair makes this site resistant to cleavage by either of the endonuclease, repair occurring on the unmethylated or nicked strand yields an AT base pair and generates a HindIII sensitive site. The heteroduplex substrate was prepared as described [32].

Mismatch repair assay using $H$. influenzae or E. coli cell-free extracts. The bacterial cells were collected by centrifugation at $4{ }^{\circ} \mathrm{C}$ and resuspended in $2 \mathrm{ml}$ of ice cold buffer containing $50 \mathrm{mM}$ Tris $-\mathrm{HCl}(\mathrm{pH}$ 7.6), $10 \%$ sucrose, $1.2 \mathrm{mM}$ DTT, and $150 \mathrm{mM} \mathrm{KCl}$. The cells were treated with $0.23 \mathrm{mg} / \mathrm{ml}$ of lysozyme for $1 \mathrm{~h}$ followed by a heat shock at $37^{\circ} \mathrm{C}$ for a time sufficient to yield a final suspension temperature of $20^{\circ} \mathrm{C}$. After centrifugation at $37,000 \mathrm{rpm}$ at $4{ }^{\circ} \mathrm{C}$ for $1 \mathrm{~h}$, the supernatant was subjected to ammonium sulfate precipitation at $70 \%$ saturation and the precipitate was collected by centrifugation.

Haemophilus influenzae. Rd cell extract, before subjecting to ammonium sulfate precipitation, was loaded on to phospho-cellulose column ( $15 \mathrm{ml}$ bed volume) equilibrated with $25 \mathrm{mM}$ potassium phosphate buffer ( $\mathrm{pH} 7.6$ ) containing $50 \mathrm{mM} \mathrm{KCl}, 0.1 \mathrm{mM}$ EDTA, and $2 \mathrm{mM}$ DTT. The column was washed with twice the bed volume of the same buffer. The wash was collected and subjected to ammonium sulfate precipitation at $70 \%$ saturation and the precipitated proteins were collected by centrifugation. The pellet was scraped into dialysis bag and dialyzed against buffer containing $25 \mathrm{mM}$ Tris- $\mathrm{HCl}(\mathrm{pH} 7.6)$, $0.1 \mathrm{mM}$ EDTA, $100 \mathrm{mM} \mathrm{KCl}$, and $2 \mathrm{mM}$ DTT for $5 \mathrm{~h}$ at $4{ }^{\circ} \mathrm{C}$ with an intermittent buffer change. The dialysate was split into $20 \mu \mathrm{l}$ aliquots and stored at $-20^{\circ} \mathrm{C}$. The stored cell-free extracts were active up to 1 month.

A typical mismatch repair reaction (final volume, $15 \mu \mathrm{l}$ ) contained $50 \mathrm{mM}$ Hepes-potassium salt ( $\mathrm{pH} 8.0$ ), $5 \mathrm{mM} \mathrm{MgCl}_{2}, \mathrm{KCl}$ (adjusted to a final concentration of $90 \mathrm{mM}$ taking into consideration the contribution of salt from added cell free extract), $1.5 \mathrm{mM}$ ATP, $0.5 \mathrm{mM}$ $\beta$-NAD ${ }^{+}, 1 \mathrm{mM}$ glutathione, $100 \mathrm{mM}$ (each) of the four deoxyribonucleoside-triphosphates, $200 \mathrm{ng}$ of covalently closed or open circular DNA heteroduplex substrate and cell free extract (150 $\mu$ g total protein) [32]. After incubation for $1 \mathrm{~h}$ at $37^{\circ} \mathrm{C}, 45 \mu \mathrm{l}$ of $25 \mathrm{mM}$ EDTA was added and the samples were extracted twice with phenol and twice with water saturated diethyl ether. DNA collected by ethanol precipitation was subjected to HindIII/ClaI double digestion in a reaction volume of $20 \mu \mathrm{l}$ and the digestion products were separated by electrophoresis on a $1 \%$ agarose gel in $89 \mathrm{mM}$ Tris-borate $/ 2 \mathrm{mM}$ EDTA at $5.3 \mathrm{~V} / \mathrm{cm}$ for $4 \mathrm{~h}$. The gel was stained with ethidium bromide and viewed on a UV-transilluminator. The DNA bands were quantitated using UVI Band V. 97 software.

Over expression and purification of $\mathrm{His}_{6}-$ MutS protein. BL21(DE3) $\mathrm{pLysS}$ cells transformed with $\mathrm{pET} 15 \mathrm{~b}$ containing the $m u t S$ gene ( $\mathrm{pNJ} 6)$ were grown overnight, picked from a single colony, at $37^{\circ} \mathrm{C}$ in $3 \mathrm{ml} \mathrm{LB}$ broth containing $100 \mu \mathrm{g} / \mathrm{ml}$ ampicillin (Amp). Six hundred milliliters of LB-Amp medium was inoculated with $3 \mathrm{ml}$ of the overnight culture and allowed to grow to an $\mathrm{OD}_{600}$ of 0.8 at $37{ }^{\circ} \mathrm{C}$. The expression of the MutS protein was achieved by the addition of IPTG to a final concentration of $0.2 \mathrm{mM}$ and the cells were allowed to grow for another $3 \mathrm{~h}$ at $37^{\circ} \mathrm{C}$. The $H$. influenzae MutS was purified as described [25]. The protein was dialyzed extensively against the buffer containing $40 \mathrm{mM}$ Tris- $\mathrm{HCl}$ (pH 7.6), 1 mM DTT, $200 \mathrm{mM} \mathrm{KCl}, 0.1 \mathrm{mM}$ EDTA, $13.3 \%$ glycerol, and stored in the same buffer with $50 \%$ glycerol at $-20{ }^{\circ} \mathrm{C}$. The purity of the protein was analyzed on $0.1 \%$ SDS $-10 \%$ polyacrylamide gel. The protein concentration was determined by using the theoretical extinction coefficient $\left(\varepsilon=63,010 \mathrm{M}^{-1} \mathrm{~cm}^{-1}\right)[36]$. Typically, approximately $1 \mathrm{mg} \mathrm{H}$. influenzae MutS protein of over $95 \%$ purity was obtained from $100 \mathrm{ml}$ culture.

Complementation assay. Cell extracts were prepared, as described before, from isogenic strains of $E$. coli, which exhibited wild type (CC106) or mutS mutant (TX2929) phenotype. In vitro complementation assays were carried out using the cell free extract, prepared from the $E$. coli mutS deficient strain (RK1517), which was complemented by the addition of the purified $H$. influenzae MutS protein exogenously ( $1 \mu \mathrm{g}$ MutS in $15 \mu \mathrm{l}$ reaction). Since glycerol is a potent inhibitor of the mismatch repair activity [41], the purified MutS protein was dialyzed against the buffer ( $40 \mathrm{mM}$ Tris- $\mathrm{HCl}(\mathrm{pH}$ 7.6), $1 \mathrm{mM}$ DTT, $200 \mathrm{mM}$ $\mathrm{KCl}$, and $0.1 \mathrm{mM}$ EDTA) without glycerol before use in the mismatch repair assay.

DNA labeling and annealing. The oligonucleotide sequences used for the preparation of different heteroduplexes are the following. The master oligonucleotide (5'-CGAGTACCGCAATGAACTTAGCACC GAGTGAATGC- $3^{\prime}$ ) when annealed with the complementary oligonucleotides 5'-GCATTCACTCGGTGCT ( ) ATTGCGGTACTCG-3' (the sequence in the square brackets differs) incorporates a mismatched base which, in all cases, is present in the same sequence context as far as possible. The base mismatch (underlined) and the corresponding sequence in the square bracket are as follows: GC, $5^{\prime}$-AA GTTC-3'; GT, $5^{\prime}$ -

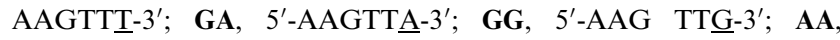
5'-AAGTAC-3'; AC, 5'-AAGTCC-3'; CT, 5'-AATTTC-3'; CC, 5'AACTTC-3'; TT, 5'-ATGTTC-3'; and $\Delta$ T, $5^{\prime}$-TAAGTTC- $3^{\prime}$. To study the effect of sequence context on the interaction of MutS with GT mismatch, the sequence in the square bracket for the master and complementary oligonucleotides used are: $5^{\prime}$-ATATGTATA- ${ }^{\prime}$ and 
5'-TATATATAT-3' for AT-rich sequence context; 5'-GCGCGCGCG$3^{\prime}$ and $5^{\prime}$-CGCGTGCGC- ${ }^{\prime}$ for GC-rich sequence context, respectively. One strand of each duplex ( $3 \mathrm{pmol})$ was labeled at the $5^{\prime}$-end with $\left[\gamma-{ }^{32} \mathrm{P}\right] \mathrm{ATP}(3 \mathrm{pmol})$ by using polynucleotide kinase as described by Sambrook et al. [37].

Electrophoretic mobility shift assay. Electrophoretic mobility shift assays were carried out as described [25]. Unlabeled poly(dI) poly(dC) $(50 \mathrm{ng} /$ reaction) was included in the reaction to reduce non-specific binding along with $1.5 \mathrm{nM}\left[\gamma^{32} \mathrm{P}\right]$-labeled DNA. Densitometric quantitation of the results was carried out using UVI Band V.97 software.

ATPase assay. ATPase activity of $H$. influenzae MutS was assayed

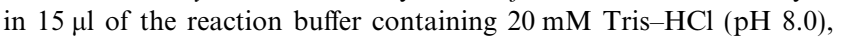
$90 \mathrm{mM} \mathrm{KCl}, 1 \mathrm{mM}$ DTT, $5 \mathrm{mM} \mathrm{MgCl}$, and ATP (concentrations as indicated) [3]. $\left[\alpha_{-}^{32} \mathrm{P}\right]$ ATP was included in the assay as a tracer. Unless otherwise specified, $H$. influenzae MutS was included at a concentration of $1 \mu \mathrm{M}$ (monomer). When present, ADP or ATP $\gamma \mathrm{S}$ was at a concentration of $5 \mathrm{mM}$. Reactions were carried out at $37^{\circ} \mathrm{C}$ for 5 or $30 \mathrm{~min}$ as described [25]. Kinetic data of ATP hydrolysis were obtained with ATP concentrations varying from $5 \mu \mathrm{M}$ to $3 \mathrm{mM}$. Kinetic constants were derived from an Eadie-Scatchard plot of $v /[S]$ vs. $v$. The results are average of at least three independent experiments.

Partial proteolysis. The limited proteolysis of $H$. influenzae MutS $(2.5 \mu \mathrm{M})$ with trypsin $(0.3 \mu \mathrm{g} / \mathrm{ml})$ was carried out at room temperature for $5 \mathrm{~min}$ in a $20 \mu \mathrm{l}$ reaction. When present, ADP or ATP was at $1 \mathrm{mM}$ and DNA, $0.8 \mu \mathrm{M}$. The reactions were quenched by the addition of PMSF ( $1 \mathrm{mM})$. The proteolytic products were separated on $12 \%$ SDSpolyacrylamide gel and silver stained.

Circular dichroism measurements. Far-UV CD spectra (200$240 \mathrm{~nm}$ ) were measured at $24{ }^{\circ} \mathrm{C}$ with a Jasco J-810 spectropolarimeter using a $0.2-\mathrm{cm}$ path-length cell. The samples were prepared in $20 \mathrm{mM}$ Tris- $\mathrm{HCl}$ ( $\mathrm{pH}$ 7.6), $90 \mathrm{mM} \mathrm{KCl}, 1 \mathrm{mM} \mathrm{MgCl} 2,5 \mathrm{mM} \beta-\mathrm{ME}$, and $5 \%$ glycerol. $H$. influenzae MutS was used at a concentration of $1 \mu \mathrm{M}$ (monomer) and ADP or ATP at $0.1 \mathrm{mM}$. DNA, when present, was $0.07 \mu \mathrm{M}$. The spectra plotted are the average of three independent scans.

\section{Results and discussion}

\section{Haemophilus influenzae cell free extract is mismatch repair proficient}

We have utilized the in vitro assay for mismatch correction to identify and characterize the mismatch repair pathway in $H$. influenzae. When the repaired GT heteroduplex is subjected to HindIII/ClaI double digestion, it is cleaved in to 3.3 and $3.1 \mathrm{~kb}$ fragments designated as the mismatch repair (MMR) products. The unrepaired GT heteroduplex would fail to give the MMR products; instead get linearized to a $6.4 \mathrm{~kb}$ fragment. $H$. influenzae cell free extract prepared in the same manner as for E. coli [32] did not give the expected mismatch repair products in the in vitro assay carried out using GT heteroduplex. Instead, two bands with different mobility were obtained (Fig. 1A, lane 2). It is likely that the cell free extract contains an unknown endonuclease. Incubating the substrate with the crude cell extract yielded a single band corresponding to the linearized substrate (Fig. 1A, lane 3), confirming the above possibility. To get rid of the contaminant, the $H$. influenzae cell extract was passed through phospho-cellulose column (see Materials and
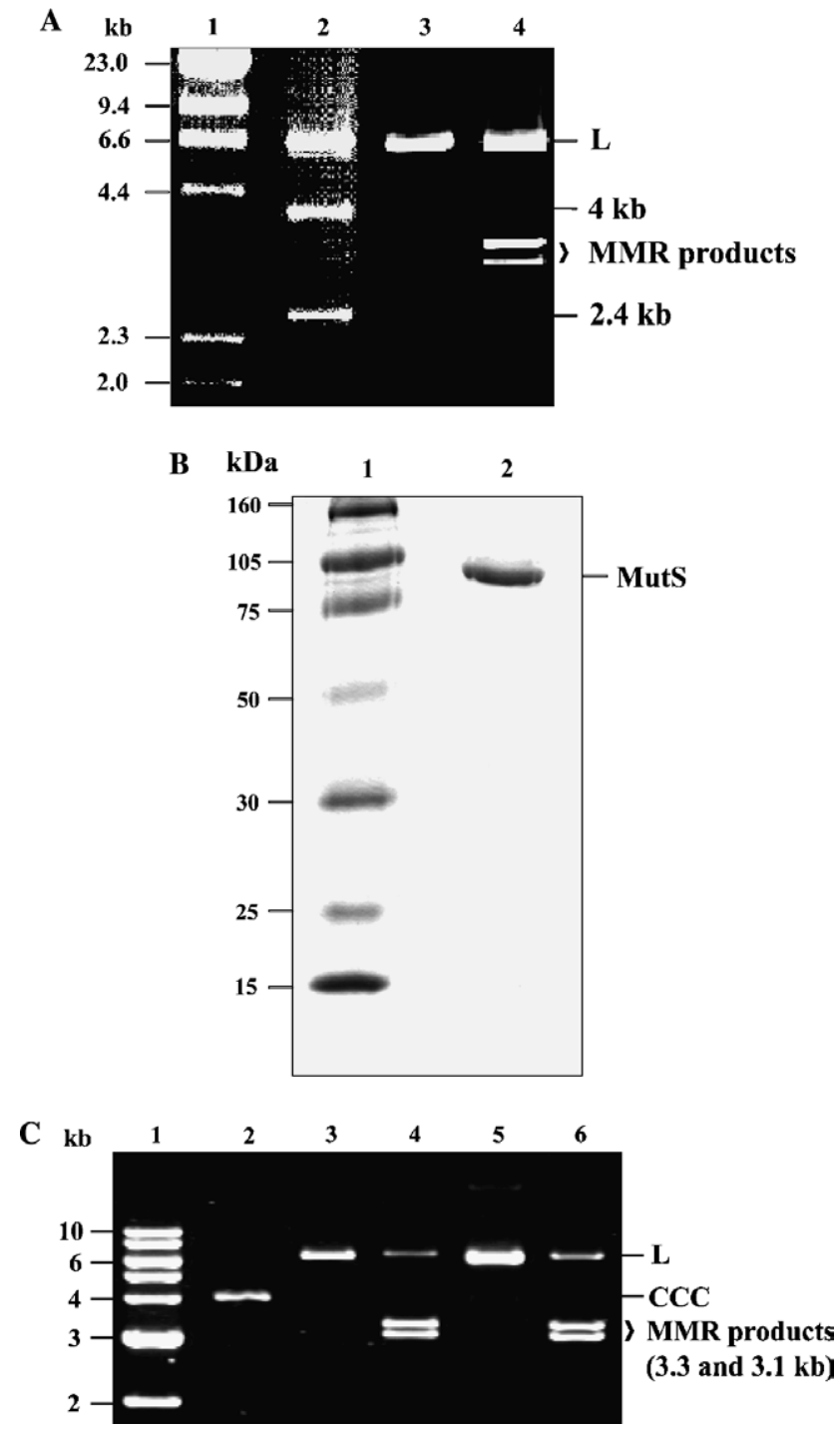

Fig. 1. In vitro mismatch repair assays. (A) Mismatch repair assays using cell free extracts from $H$. influenzae. Cell extract before and after passing through the phospho-cellulose column was used for the mismatch repair assay. Lane 1, molecular weight markers; lane 2, open circular heteroduplex DNA incubated with cell extract before passing through phospho-cellulose column and subsequent digestion with HindIII and ClaI; lane 3, same as lane 2 but not subjected to HindIII/ ClaI digestion and lane 4, same as lane 2 but cell extract passed through phospho-cellulose column. (B) SDS-PAGE analysis of purified recombinant $\mathrm{His}_{6}$-tagged MutS protein of $H$. influenzae visualized by staining with Coomassie blue. Lanes 1 and 2 are molecular weight markers and purified MutS, respectively. (C) In vitro complementation assay using purified $H$. influenzae MutS protein. Lane 1, $1 \mathrm{~kb}$ ladder; lane 2, untreated CCC heteroduplex; lane 3, same as lane 2, but digested with HindIII and ClaI. Lanes 4 and 5 are reactions with the cell extracts prepared from AB1157 and RK1517 strains, respectively. Lane 6 , repair assay with the cell extract of RK1517 complemented by the exogenous addition of purified H. influenzae MutS protein ( $1 \mu \mathrm{g}$ in $15 \mu \mathrm{l}$ reaction) (CCC, covalently closed circular; OC, open circular; and L, linear).

methods). This dialyzed cell extract was highly proficient in repairing the mismatches giving expected mismatch repair products of 3.3 and $3.1 \mathrm{~kb}$ (Fig. 1A, lane 4). 
Optimum repair activity was observed when the salt concentration was maintained between 50 and $90 \mathrm{mM}$ $\mathrm{KCl}$ (data not shown). The final concentration of $\mathrm{KCl}$ in the reaction was calculated taking into consideration the contribution of salt from the reaction buffer and the added cell free extract.

\section{Complementation assay of $H$. influenzae mutS gene product}

Earlier studies on complementation of mut deficient E. coli strains with mut genes from other bacteria reported successful complementation in the case of the closely related mutL and mutS genes from Salmonella typhimurium, reduced complementation with the mutS gene of Pseudomonas putida and no complementation with mutS or $m u t L$ genes from more distantly related organisms like Thermus aquaticus and Streptococcus pneumoniae $[6,21,29]$. Therefore, it was of interest to find whether the addition of purified MutS protein could confirm its functional role in mismatch repair. For in vitro complementation assays, the purified recombinant $H$. influenzae
MutS protein (Fig. 1B) was exogenously added to the cell extract prepared from E. coli RK1517 strain (Fig. 1C). Assays with the cell extract from wild-type E. coli strain was repair proficient (Fig. 1C, lane 4) whereas extract from the mutant was not (Fig. 1C, lane 5). Addition of the purified $H$. influenzae MutS exogenously (1 $\mu \mathrm{g}$ MutS) resulted in the mismatch repair deficient cell extracts regaining their ability to correct the base mispairs (Fig. 1C, lane 6). The repair bands were quantitated densitometrically using UVI Band V.97 software. The degree of complementation was observed to be high (up to approximately $80 \%$ ), considering the amount of mismatch repair products obtained in the repair assays.

Affinity of MutS for heteroduplexes containing different base mismatches

Band shift analysis was used to study the interaction between $H$. influenzae MutS and synthetic DNA fragments containing all possible DNA mismatches as well as one-nucleotide loop (represented as $\Delta T$ ) (Fig. 2A,
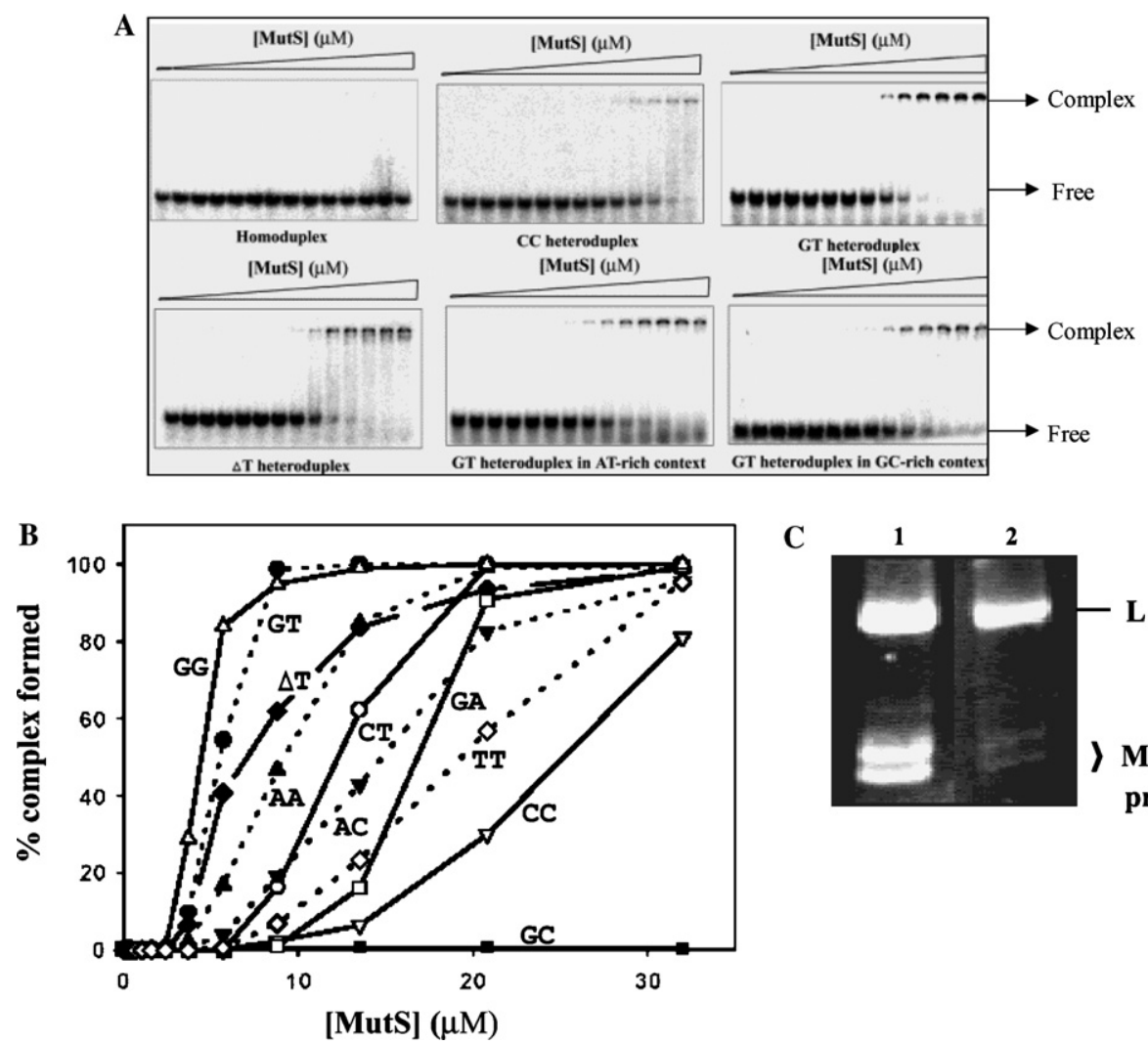

C

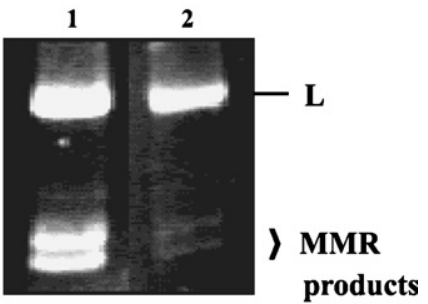

Fig. 2. (A) Gel mobility shift analysis of interaction between $H$. influenzae MutS and DNA duplexes containing mismatched bases carried out as described in Materials and methods. Endlabeled DNA $(1.5 \mathrm{nM})$ was incubated with increasing concentrations of MutS (0-32 nM as monomer). The individual mismatches are shown below each panel. (B) MutS binding plot derived from the gel mobility shift assays are shown in (A). The data were obtained by a quantitative analysis of the phosphor images using UVI Band V.97 software. The plotted data are the average of at least three independent experiments. The symbols used are as follows: GC (black square), GG (open triangle), GT (black circle), AC (inverted black triangle), AA (black triangle), TT (open diamond), $\Delta T$ (black diamond), GA (open square), CT (open circle), and CC (inverted open triangle). (C) $H$. influenzae cell free extract repairs different mismatches with varying efficiencies. A representative repair assay using GT (lane 1) and AC (lane 2) DNA heteroduplexes $(\mathrm{L}$, linear). 
data shown for only GT, $\Delta T$, CC mismatches). In all cases, the addition of MutS caused decrease in the mobility of DNA to different extents. These changes were dependent on the concentration of MutS, such that in several instances almost no free DNA was evident at the highest protein concentration used. We measured the disappearance of free DNA with increasing concentrations of His $_{6}$-MutS from which the percentage of retarded complex was calculated. The quantitative analysis for the heteroduplexes yielded the binding plots shown in Fig. 2B. Though E. coli MutS is shown to use a common binding mode to recognize a wide range of mismatches [35], reports have shown that it has variable affinity for different mismatches, the order being $\Delta T>\mathrm{GT}>\mathrm{GG}>\mathrm{AA} \approx \mathrm{TT} \approx \mathrm{TC}>\mathrm{CA}>\mathrm{GA}>\mathrm{CC}>$ $\mathrm{GC}[12]$. From the analysis of our binding data, it can be concluded that the $H$. influenzae MutS exhibited differences in its affinities for the various mismatched bases and the order of affinity observed being $\mathrm{GG}>\mathrm{GT}>\Delta T$ $>\mathrm{AA}>\mathrm{AC} \approx \mathrm{CT}>\mathrm{TT}>\mathrm{GA}>\mathrm{CC}>\mathrm{GC}$. In contrast to $E$. coli MutS [12], we did not find any retarded complex when the radiolabeled Watson-Crick homoduplex was used in the absence (data not shown) or presence of unlabeled poly(dI).poly(dC) (Fig. 2A, panel Homoduplex). This could be due to the poor stability of the MutS-homoduplex complex compared to its binding to the heteroduplex DNA. The mismatch binding hierarchy is different to that of MutS from other organisms but this could be a reflection of MutS function in $H$. influenzae such as dinucleotide tract recognition. These differences might be associated with the role of mismatch repair in hyper mutability of contingency loci of H.influenzae.

To evaluate the repair efficiency of heteroduplex containing different base mismatches, assay was carried out using substrates containing either GT or AC base mismatch. Both these mismatches were located at the same position within the heteroduplex molecules and were embedded within the same sequence environment. In AC heteroduplex, the mismatch is present in the recognition sequence of XhoI instead of HindIII [32]. Both these substrates were corrected with different efficiencies in vitro (Fig. 2C). Analysis of the results have shown that GT was corrected more efficiently (Fig. 2C, lane 1 ), with AC being repaired poorly compared to GT mispair (Fig. 2C, lane 2).

Escherichia coli mismatch repair system has been shown to correct transition mismatches better than transversions, with GT and AC mismatches being repaired at a rate of $43-61 \%$ of that observed for GT mismatch, depending on the strand on which the repair occurred [39]. It was, therefore, surprising to note that the $H$. influenzae MutS binds AC mismatch to a lesser extent than GT. The hierarchy of apparent affinities of MutS for at least two mispairs (GT and AC) does correlate well with the efficiencies with which these mispairs are replaced in the in vitro assay. We have analyzed the effect of sequence context on binding of $H$. influenzae MutS to the DNA mismatch. Heteroduplexes containing a GT mismatch in two environments, surrounded by alternating $\mathrm{A}$ and $\mathrm{T}$ or $\mathrm{G}$ and $\mathrm{C}$, were used for the binding assays. It was observed that under sub-saturating concentrations of $H$. influenzae MutS, the binding was marginally better when the GT mismatch was embedded in an AT rich sequence rather than GC (Fig. 2A). It is interesting to recall that the $H$. influenzae genome is AT rich $(61 \%)$ in contrast to the $E$. coli genome, which has a GC content of 53\% [11]. E. coli MutS protein, on the other hand, binds to GT mismatch flanked by GC rich sequences better than to GT mismatch flanked by AT rich regions [12]. The pathogenicity islands in $H$. influenzae are found to have higher GC content [23] when compared to the bulk of the genome. It could be speculated that the less affinity of $H$. influenzae MutS to mismatched bases in GC-rich sequences could lead to decreased efficiency of repair in such regions and hence contributing to high level of variability. The in vivo significance of this observation, in $H$. influenzae, is yet to be studied in detail.

Haemophilus influenzae MutS was found to be capable of binding to single-stranded DNA (Fig. 3A, lanes 2-7) and the DNA-protein complex could be competed out when excess of unlabeled single-stranded DNA was included in the reaction (Fig. 3A, lanes 9-14). This observation of $H$. influenzae MutS binding to singlestranded DNA is surprising, though its affinity is much less compared to that for GT or GG heteroduplex DNA. Blackwell et al. [9] reported the binding of hMut$\mathrm{S} \alpha$ to high molecular weight ssDNA. It is quite possible that MutS encounters single-stranded DNA regions during the exonucleolytic cleavage step elicited upon recognition of the mismatched base. The in vivo significance of this observation at present is unclear.

\section{Effect of nucleotide on the mismatch binding by H. influenzae MutS}

In addition to the mismatch binding activity, E. coli MutS is capable of hydrolyzing ATP. The nucleotide hydrolytic center of MutS is necessary for the biological activity of this protein in vivo [22]. In the presence of ATP, MutS was found to dissociate quickly from linear heteroduplexes or heteroduplexes blocked at only one end [38]. MutS dimers were found to assemble into higher order oligomers in a concentration-dependent manner and ATP binding shifted this equilibrium in favor of the assembly $[7,8]$.

To study the effect of nucleotide on the mismatch binding activity of $H$. influenzae MutS, the assays were carried out in the presence of ATP at $4{ }^{\circ} \mathrm{C}$ as well as room temperature $\left(24^{\circ} \mathrm{C}\right)$. Upon prolonged electrophoresis (upto $6 \mathrm{~h}$ ), two distinct complexes, $\mathrm{C} 1$ and $\mathrm{C} 2$, were 
$\mathbf{A}$

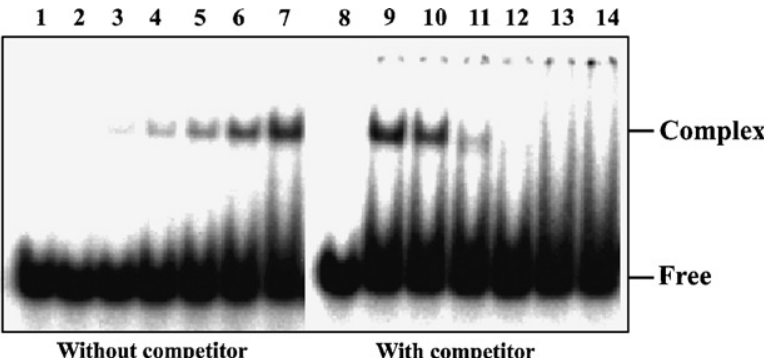

B

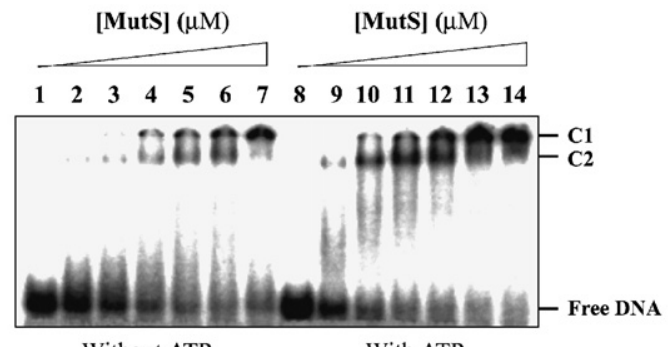

Without ATP

With ATP

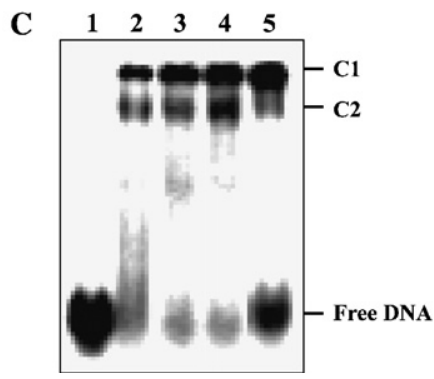

Fig. 3. (A) Haemophilus influenzae MutS binding to single-stranded DNA. End-labeled ssDNA $(1.5 \mathrm{nM})$ was incubated with increasing concentrations of MutS (0-50 $\mu \mathrm{M}$ as monomer) (lanes 1-7). Lanes 814 represent assays with $1.5 \mathrm{nM}$ labeled ssDNA incubated with $50 \mu \mathrm{M}$ MutS and increasing concentrations of unlabeled ssDNA (0-500 nM). Lane 8, no protein control; lane 9, with MutS but no competitor; lanes $10-14$ are reactions with $2,15,60,250$, and $500 \mathrm{nM}$ of unlabeled competitor ssDNA, respectively. Samples were analyzed as described in Materials and methods. (B) Effect of nucleotide on the mismatch binding property of $H$. influenzae MutS. Gel mobility shift assay in which $1.5 \mathrm{nM}$ of radio-labeled GT heteroduplex was incubated with increasing concentration of MutS $(0-50 \mu \mathrm{M})$ in the absence (lanes 1-7) or presence (lanes 8-14) of $1 \mathrm{mM}$ ATP and the samples were analyzed on $6 \%$ native polyacrylamide gel. (C) MutS binding assays in the absence of any nucleotide (lane 2); in the presence of $1 \mathrm{mM}$ ADP (lane 3) or ATP (lane 4) or ATP $\gamma$ S (lane 5). Lane 1, no protein control.

obtained (Figs. 3B and C). The percentage of proteinDNA complex in the presence of ATP was higher than in the absence of ATP (Fig. 3B, compare lanes 3-7 with lanes 10-14 and Fig. 3C, compare lane 2 with lane 4) or in the presence of ADP (Fig. 3C, lane 3). From the differences in the mobility of the complexes formed, we suggest that complex $\mathrm{C} 1$ could be a tetramer or higher order oligomer whereas complex $\mathrm{C} 2$ could be a dimer of MutS. The presence of the non-hydrolyzable ATP analog, ATP $\gamma \mathrm{S}$, greatly reduced the amount of DNAprotein complex in complex $\mathrm{C} 2$ (Fig. 3C, lane 5). From the above observations it is suggested that, ATP favors the formation of $H$. influenzae MutS dimers which later, in a protein concentration-dependent manner, result in higher order oligomerization. Sedimentation velocity and gel filtration studies by Modrich and co-workers $[7,8]$ indicated that $E$. coli MutS dimers assembled into higher order structures in the presence of ATP and this dimer-to-tetramer assembly promoted DNA binding by MutS.

\section{ATPase activity of $H$. influenzae MutS}

Thin layer chromatography analysis of $H$. influenzae MutS ATPase activity was carried out using $\left[\alpha-{ }^{32} \mathrm{P}\right] \mathrm{ATP}$ as a tracer along with unlabeled ATP. Spontaneous hydrolysis of ATP in the absence of any protein was less than $5 \%$.

Using Eadie-Scatchard plot, kinetic parameters were calculated (Fig. 4A). The $k_{\text {cat }}$ of $H$. influenzae MutS ATPase was found to be $19.4 \pm 0.5 \mathrm{~min}^{-1}$ and $K_{\mathrm{m}}$ (ATP) was $359.4 \pm 35.7 \mu \mathrm{M}$ at $\mathrm{pH} 8.0$ and $37^{\circ} \mathrm{C}$. The kinetic parameters for $E$. coli MutS ATPase reported so far vary considerably; reported $K_{\mathrm{m}}$ values for ATP vary from 8.7 to $116 \mu \mathrm{M}$ and that for $k_{\text {cat }}$ falls in the range of $0.008-13.2 \mathrm{~min}^{-1}[5,7,27,31]$.

The kinetics of ATP hydrolysis by $H$. influenzae MutS in the presence of DNA was also determined (Fig. 4A). In the presence of GT heteroduplex, the MutS ATPase showed a $K_{\mathrm{m}}$ of $375.1 \pm 8.2 \mu \mathrm{M}$ ATP and the maximal hydrolysis rate $\left(k_{\text {cat }}\right.$ was $37.6 \pm 1 \mathrm{~min}^{-1}$. When ssDNA was included in the reaction, the $K_{\mathrm{m}}$ and $k_{\text {cat }}$ were $517.6 \pm 15.2 \mu \mathrm{M}$ ATP and $63.2 \pm 1.6 \mathrm{~min}^{-1}$, respectively. H. influenzae MutS ATPase activity is stimulated 2fold in the presence of GT heteroduplex and about 3.5-fold in the presence of single-stranded DNA. Interestingly, in the presence of DNA, substrate inhibition at higher concentrations of ATP was observed, which was highly significant when ssDNA was included in the reaction (data not shown). This could be indicative of the differential regulation of the activities of MutS upon encounter with single-stranded or duplex DNA during the repair process.

Genetic analysis has indicated that the nucleotide hydrolytic center of bacterial MutS is required for mismatch repair in vivo [31], and poorly hydrolyzed ATP analogues have been shown to inhibit steps of the mismatch repair reaction in vitro [33]. ADP, ATP $\gamma \mathrm{S}$ (Fig. 4B) and AMP-PNP (data not shown) were able to inhibit the enzyme activity of $H$. influenzae MutS ATPase. Inhibition of ATPase activity by ADP was reported in E. coli MutS as well [7]. It was interesting to observe, that the $H$. influenzae MutS ATPase inhibition by ADP (product inhibition) was considerably reduced in the presence of DNA (Fig. 4B, compare bar 3 with bar 4). Blackwell et al. [10] have shown that E. coli MutS has the highest mismatch specificity in the absence of nucleotide or in the presence of ADP. 

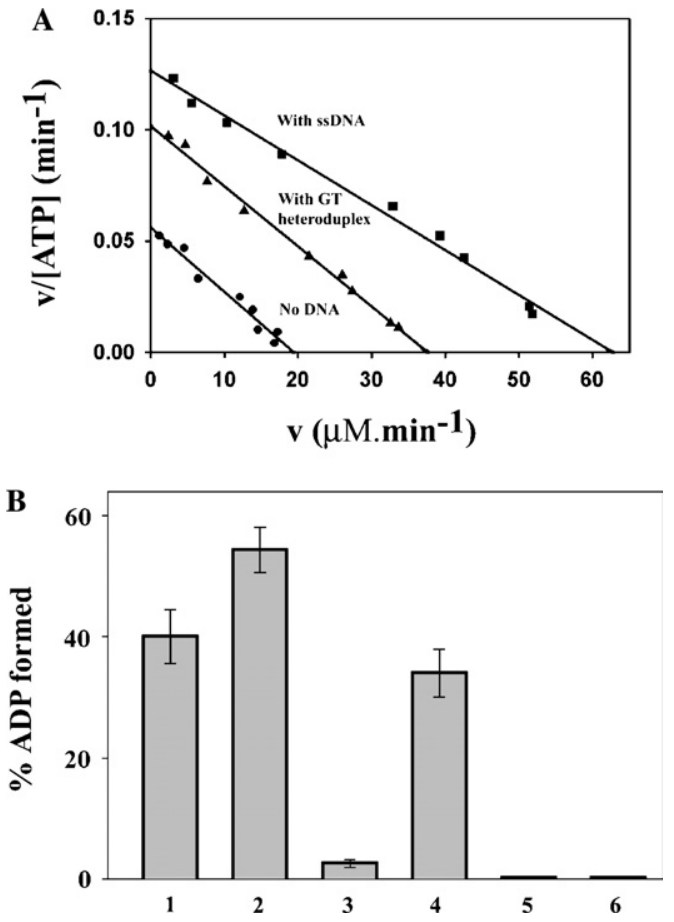

Fig. 4. (A) Eadie-Scatchard plot of $H$. influenzae MutS ATPase. The assays were done in the absence or presence of GT heteroduplex or ssDNA. The data points of $v /[\mathrm{ATP}]$ vs. $v$ for the assay in the absence of DNA were fitted to a straight line with a slope of -0.003 and $y$-intercept of $0.0562\left(R^{2}=0.9628\right)$. When present, DNA is used at a DNA to protein ratio of 1:3. Data points obtained for reactions in the presence of GT heteroduplex were fitted to a straight line with a slope of -0.0027 and $y$-intercept of $0.1018\left(R^{2}=0.9925\right)$. For reactions with single-stranded DNA, the data points obtained were fitted to a straight line with a slope of -0.002 and $y$-intercept of $0.1266\left(R^{2}=0.9906\right)$. Kinetic parameters such as $K_{\mathrm{m}}$ and $k_{\text {cat }}$ were calculated from the Eadie-Scatchard plots. The results are the average of at least three independent experiments. (B) Effect of nucleotide analogs on MutS ATPase activity. The assays were done for $30 \mathrm{~min}$ at $37^{\circ} \mathrm{C}$ with $1 \mu \mathrm{M}$ MutS, $750 \mu \mathrm{M}$ ATP and in the absence or presence of ssDNA, the ratio of DNA to protein being 1:3. When present, ADP or ATP $\gamma \mathrm{S}$ was $5 \mathrm{mM}$. Bar 1, protein alone; bar 2, protein with ssDNA; bar 3, protein with ADP but no ssDNA; bar 4, protein with ADP and ssDNA; bar 5, protein with ATP $\gamma \mathrm{S}$ but no ssDNA; bar 6, protein with ATP $\gamma \mathrm{S}$ and ssDNA. The data were obtained by a quantitative analysis of the phosphor images using UVI Band V.97 software. Results are the average of at least three independent trials. Standard deviations are indicated by error bars.

Although our experiments in this study do not address which step is rate-limiting, we suggest that the rate-limiting step of MutS ATP hydrolysis activity could be the product (ADP) release and this is likely to be facilitated by the binding of $H$. influenzae MutS to DNA. This is reflected in the increased turnover of ATP hydrolysis by $H$. influenzae MutS in the presence of DNA (Fig. 4A). Both the Hingorani [1] and Modrich [7] laboratories have pre steady-state analyses that suggest which in the presence of ATP and mismatched DNA, a step after ATP binding but at or before chemistry becomes rate-limiting. It has been demonstrated that the level of ATP hydrolysis by $H$. influenzae MutS was higher when it encounters DNA ends [25] or in the presence of single-stranded DNA (Fig. 4A). DNA binding is shown to stimulate exchange of ADP for ATP $[7,18]$ and ATP binding decreases the affinity for heteroduplexes [10,27]. Repeated binding of MutS to DNA with the concurrent exchange of ADP for ATP and the subsequent dissociation from DNA ends or at single-stranded DNA regions coupled with ATP hydrolysis could explain the alleviation of ADP inhibition of $H$. influenzae MutS ATPase in the presence of DNA.

\section{DNA and nucleotide-dependent conformational changes in H. influenzae MutS}

The conformation of Thermus thermophilus MutS in solution was found to be influenced by the presence of nucleotide, where in the ATP-bound form has the most compact conformation, the ADP-bound form was largely stretched and the nucleotide-free MutS attains a conformation intermediate between the two [28]. Joshi et al. [26] have shown that E. coli MutS undergoes conformational transition upon binding ATP or ADP or ATP $\gamma$ S, but in the presence of DNA, only ATP or ATP $\gamma \mathrm{S}$ was able to bring about similar effect.

In order to understand the influence of DNA and nucleotide on the conformational changes acquired by $H$. influenzae MutS, we studied the limited proteolysis pattern by trypsin digestion. The proteolytic products obtained for free MutS as well as in the presence of ADP or ATP were largely similar when analyzed on $12 \%$ SDS-polyacrylamide gel using silver staining. (Fig. 5A, lanes 7-9). It is quite clear that, in the presence of nucleotide and DNA, MutS undergoes drastic conformational change, which results in the absence of several proteolytic products in the size range of $25-65 \mathrm{kDa}$ (Fig. 5A, marked by arrowheads) as visualized on the polyacrylamide gel (Fig. 5A, compare lanes 3-5 with lanes 7-9). Circular dichroism spectra of $H$. influenzae MutS in the absence or presence of nucleotide reveals that the protein is structurally disordered (Fig. 5B). The spectra for MutS in the presence of nucleotide and/or DNA have been subtracted from those for DNA and or nucleotide alone. The nucleotide concentration in the samples had to be limited to $0.1 \mathrm{mM}$, as higher concentrations of it resulted in increased HT[V] that interfered with the recording of the CD spectra. The structural perturbation and disorder of MutS were observed when homoduplex DNA was included irrespective of the presence or absence of nucleotide (Fig. 5C). This clearly indicates that the ordered and compact functional conformation of MutS can be achieved only through the concerted effects of both ATP and heteroduplex DNA. The presence of ATP and heteroduplex DNA conferred MutS with a more 

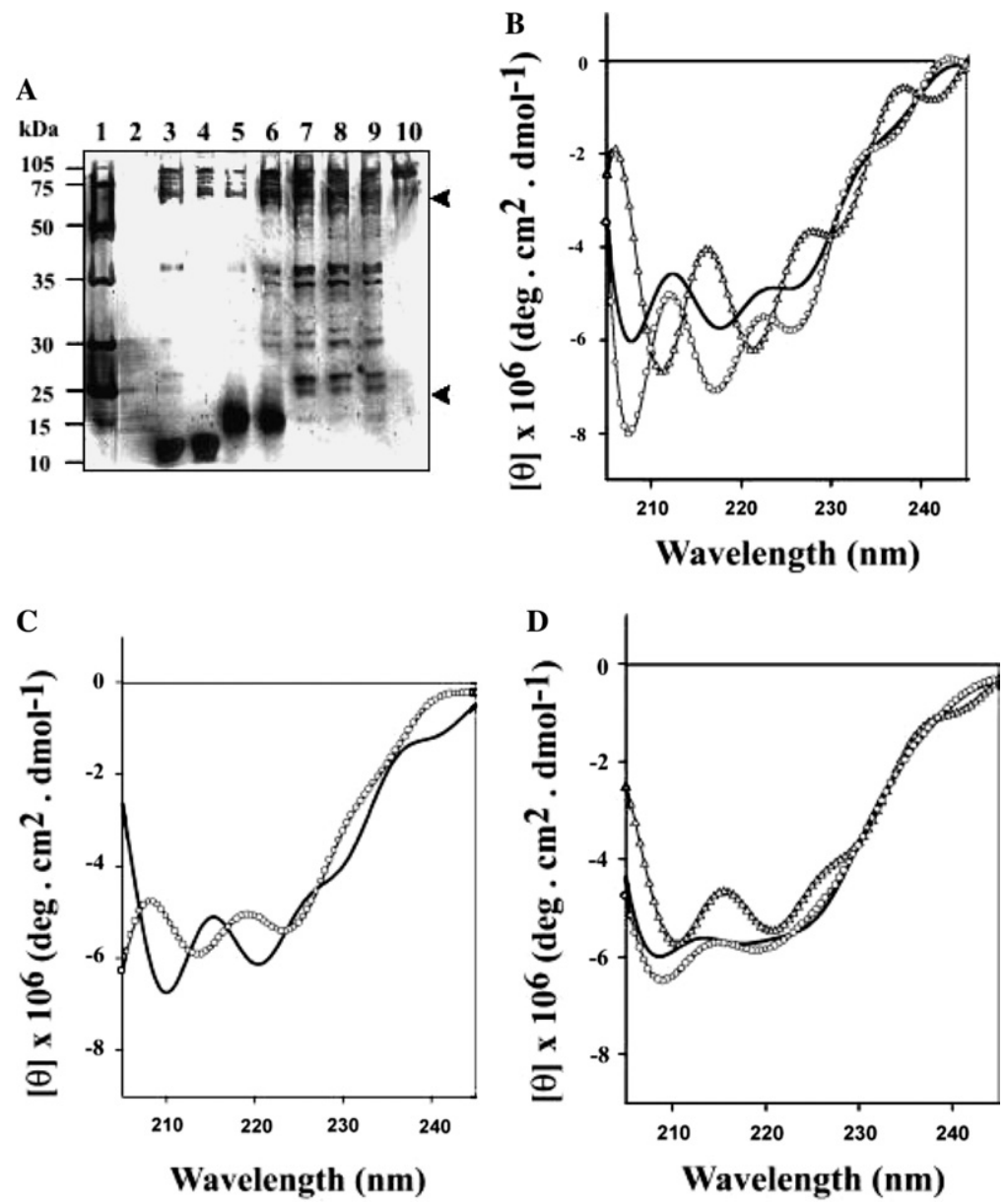

Fig. 5. Conformational changes in H. influenzae MutS. (A) Limited proteolysis. Partial tryptic digestion $(0.3 \mu \mathrm{g} / \mathrm{ml})$ of $\mathrm{MutS}(2.5 \mu \mathrm{M})$ was performed as described in Materials and methods. Lane 1, molecular weight markers; lane 2, trypsin alone; lane 3, MutS trypsinized in the presence of ssDNA and ATP; lane 4, MutS trypsinized with ssDNA and ADP; lane 5, MutS trypsinized with GT heteroduplex and ATP; lane 6, MutS trypsinized with GT heteroduplex and ADP; lane 7, MutS with trypsin treatment in the absence of DNA and nucleotide; lane 8, MutS trypsinized in the presence of ATP; lane 9, MutS trypsinized in the presence of ADP; lane 10, untreated MutS. (B) Far-UV CD spectra of $H$. influenzae MutS in the absence or presence of nucleotides. No nucleotide (thick line), $0.1 \mathrm{mM}$ ADP (triangle) or $0.1 \mathrm{mM}$ ATP (circle) was added to the samples. (C) MutS CD spectra with homoduplex DNA in the absence (thick line) or presence (circle) of $0.1 \mathrm{mM} \mathrm{ATP.} \mathrm{(D)} \mathrm{MutS} \mathrm{CD} \mathrm{spectra} \mathrm{in} \mathrm{the} \mathrm{presence} \mathrm{of} \mathrm{GT}$ heteroduplex DNA with no nucleotide (thick line), $0.1 \mathrm{mM}$ ADP (triangle) or $0.1 \mathrm{mM}$ ATP (circle) added to the samples. The contributions of DNA or nucleotide to ellipticity were subtracted.

ordered structure. This is reflected in the increase in its ellipticity compared to conditions where MutS and heteroduplex were present without nucleotide or when ADP was included in the sample (Fig. 5D).

A challenging problem in the DNA mismatch repair pathway is to delineate the consequences of conformational changes of MutS upon mismatch/nucleotide binding thereby bringing about the recruitment of other protein components to the repair site. It could be anticipated that the conformational switch of MutS dimer helps in the formation of its MutL-interaction domain. Identification of the amino acid residues that mediate MutS-MutL interaction in conjunction with the binding of nucleotide can lead to the understanding of the coupling of initial mismatch recognition signal with the down stream processes of DNA mismatch repair.

\section{Acknowledgments}

We thank Dr. Paul Modrich, Duke University Medical Center, USA and Dr. Peter Friedhoff, Justus-Liebig University, Germany for kindly supplying the E. coli strains. We thank Dr. Meenakshi Balganesh, Astra Zeneca India, for providing Haemophilus influenzae $\mathrm{Rd}$ strain. N.J. acknowledges the members of the DNR laboratory for stimulating discussions. We thank S. Arathi for technical support. N.J. and V.D. gratefully acknowledge Senior Research Fellowships from the Council of Scientific and Industrial Research, Govt. of India. We acknowledge the Department of Biotechnology, Govt. of India, for the award of a research grant in support of this work as well as the financial support through the DBT Proteomics Program. 


\section{References}

[1] E. Antony, M.M. Hingorani, Mismatch recognition-coupled stabilization of Msh2-Msh6 in an ATP-bound state at the initiation of DNA repair, Biochemistry 42 (2003) 7682-7693.

[2] K.G. Au, K. Welsh, P. Modrich, Initiation of methyl-directed mismatch repair, J. Biol. Chem. 267 (1992) 12142-12148.

[3] C. Ban, M. Junop, W. Yang, Transformation of MutL by ATP binding and hydrolysis: a switch in DNA mismatch repair, Cell 97 (1999) 85-97.

[4] C.D. Bayliss, W.A. Sweetman, E.R. Moxon, Mutations in polI but not mut SLH destabilize Haemophilus influenzae tetranucleotide repeats, EMBO J. 21 (2002) 1465-1476.

[5] I. Biswas, G. Obmolova, M. Takahashi, A. Herr, M.A. Newman, W. Yang, P. Hsieh, Disruption of the helix-u-turn-helix motif of MutS protein: loss of subunit dimerization, mismatch binding and ATP hydrolysis, J. Mol. Biol. 305 (2001) 805-816.

[6] I. Biswas, P. Hsieh, Identification and characterization of a thermo stable MutS homolog from Thermus aquaticus, J. Biol. Chem. 271 (1996) 5040-5048.

[7] K.P. Bjornson, D.J. Allen, P. Modrich, Modulation of MutS ATP hydrolysis by DNA cofactors, Biochemistry 39 (2000) 31763183.

[8] K.P. Bjornson, L.J. Blackwell, H. Sage, C. Baitinger, D. Allen, P. Modrich, Assembly and molecular activities of the MutS tetramer, J. Biol. Chem. 278 (2003) 34667-34673.

[9] L.J. Blackwell, K.P. Bjornson, Paul Modrich, DNA-dependent activation of the hMutS $\alpha$ ATPase, J. Biol. Chem. 273 (1998) 32049-32054.

[10] L.J. Blackwell, K.P. Bjornson, D.J. Allen, P. Modrich, Distinct MutS DNA-binding modes that are differentially modulated by ATP binding and hydrolysis, J. Biol. Chem. 276 (2001) 3433934347.

[11] F.R. Blattner, G. Plunkett, C.A. Bloch, N.T. Perna, V. Burland, M. Riley, J. Collado-Vides, J.D. Glasner, C.K. Rode, G.F. Mayhew, J. Gregor, N.W. Davis, H.A. Kirkpatrick, M.A. Goeden, D.J. Rose, B. Mau, Y. Shao, The complete genome sequence of Escherichia coli K-12, Science 277 (1997) 1453-1474.

[12] J. Brown, T. Brown, K.R. Fox, Affinity of mismatch-binding protein MutS for heteroduplexes containing different mismatches, Biochem. J. 354 (2001) 627-633.

[13] V. Burdett, C. Baitinger, M. Viswanathan, S.T. Lovett, P Modrich, In vivo requirement for RecJ, ExoVII, ExoI, and ExoX in methyl-directed mismatch repair, Proc. Natl. Acad. Sci. USA 98 (2001) 6765-6770.

[14] D.L. Cooper, R.S. Lahue, P. Modrich, Methyl-directed mismatch repair is bi-directional, J. Biol. Chem. 268 (1993) 11823-11829.

[15] V. Dao, P. Modrich, Mismatch, MutS-, MutL-, and helicase IIdependent unwinding from the single-stranded break of an incised heteroduplex, J. Biol. Chem. 273 (1998) 9202-9207.

[16] R.D. Fleischmann, M.D. Adams, O. White, R.A. Clayton, E.F. Kirkness, A.R. Kerlavage, C.J. Bult, J.F. Tomb, B.A. Dougherty, J.M. Merrick, et al., Whole-genome random sequencing and assembly of Haemophilus influenzae Rd, Science 269 (1995) 496512.

[17] P. Friedhoff, B. Sheybani, E. Thomas, C. Merz, A. Pingoud, Haemophilus influenzae and Vibrio cholerae genes for mutH are able to fully complement a mutH defect in Escherichia coli, FEMS Microbiol. 208 (2002) 123-128.

[18] S. Gradia, D. Subramanian, T. Wilson, S. Acharya, A. Makhov, J. Griffith, R. Fishel, hMSH2-hMSH6 forms a hydrolysisindependent sliding clamp on mismatched DNA, Mol. Cell 3 (1999) 255-261.

[19] M. Grilley, K.M. Welsh, S.S. Su, P. Modrich, Isolation and characterization of the Escherichia coli mutL gene product, J. Biol. Chem. 264 (1989) 1000-1004.
[20] M. Grilley, J. Griffith, P. Modrich, Bidirectional excision in methyl-directed mismatch repair, J. Biol. Chem. 268 (1993) 11830-11837.

[21] L.T. Haber, P.P. Pang, D.I. Sobell, J.A. Mankovich, G.C. Walker, Nucleotide sequence of the Salmonella typhimurium mutS gene required for mismatch repair: homology of MutS and HexA of Streptococcus pneumoniae, J. Bacteriol. 170 (1988) 197-202.

[22] L.T. Haber, G.C. Walker, Altering the conserved nucleotide binding motif in the Salmonella typhimurium MutS mismatch repair protein affects both its ATPase and mismatch binding activities, EMBO J. 10 (1991) 2707-2715.

[23] J. Hacker, G. Blum-Oehler, I. Muhldorfer, H. Tschape, Pathogenicity islands of virulent bacteria: structure, function and impact on microbial evolution, Mol. Microbiol. 23 (1997) 1089-1097.

[24] D.W. Hood, E.R. Moxon, Lipopolysaccharide phase variation in Haemophilus and Neisseria, in: H. Brude, S.M. Opal, S.N. Vogel, D.C. Morrison (Eds.), Endotoxin in Health and Disease, Marcel Dekker, New York, 1999, pp. 39-54.

[25] N. Joseph, R. Sawarkar, D.N. Rao, DNA mismatch correction in Haemophilus influenzae: characterization of MutL, MutH and their interaction, DNA Repair 3 (2004) 1561-1577.

[26] A. Joshi, S. Sen, J.B. Rao, ATP-hydrolysis-dependent conformational switch modulates the stability of MutS-mismatch complexes, Nucleic Acids Res. 28 (2000) 853-861.

[27] M.S. Junop, G. Obmolova, K. Rausch, P. Hsieh, W. Yang, Composite active site of an ABC ATPase: MutS uses ATP to verify mismatch recognition and authorize DNA repair, Mol. Cell 7 (2001) $1-12$.

[28] R. Kato, M. Kataoka, H. Kamikubo, S. Kuramitsu, Direct observation of three conformations of MutS protein regulated by adenine nucleotides, J. Mol. Biol. 309 (2001) 227-238.

[29] Y. Kurusu, T. Narita, M. Suzuki, T. Watanabe, Genetic analysis of an incomplete mut $\mathrm{S}$ gene from Pseudomonas putida, J. Bacteriol. 182 (2000) 5278-5279.

[30] R.S. Lahue, K.G. Au, P. Modrich, DNA mismatch correction in a defined system, Science 245 (1989) 160-164.

[31] M.H. Lamers, H.H. Winterwerp, T.K. Sixma, The alternating ATPase domains of MutS control DNA mismatch repair, EMBO J. 22 (2003) 746-756.

[32] A.L. Lu, S. Clark, P. Modrich, Methyl-directed repair of DNA base pair mismatches in vitro, Proc. Natl. Acad. Sci. USA 80 (1983) 4639-4643.

[33] A.L. Lu, K. Welsh, S. Clark, S.S. Su, P. Modrich, Repair of DNA base pair mismatches in extracts of Escherichia coli, Cold Spring Harbor Symp. Quant. Biol. 49 (1984) 589-596.

[34] P. Modrich, R.S. Lahue, Mismatch repair in replication fidelity, genetic recombination, and cancer biology, Annu. Rev. Biochem. 65 (1996) 101-133.

[35] G. Natrajan, M.H. Lamers, J.H. Enzlin, H.H.K. Winterwerp, A. Perrakis, T.K. Sixma, Structures of Escherichia coli DNA mismatch repair enzyme MutS in complex with different mismatches: a common recognition mode for diverse substrates, Nucleic Acids Res. 31 (2003) 4814-4821.

[36] C.N. Pace, F. Vajdos, L. Fee, G. Grimsley, T. Gray, How to measure and predict the molar absorption coefficient of a protein, Protein Sci. 4 (1995) 2411-2423.

[37] J. Sambrook, D.W. Russel, Molecular Cloning: A Laboratory Manual, third ed., Cold Spring Harbor Laboratory, Cold Spring Harbor, NY, 2001.

[38] M.J. Schofield, S. Nayak, T.H. Scott, C. Du, P. Hsieh, Interaction of Escherichia coli MutS and MutL at a DNA mismatch, J. Biol. Chem. 276 (2001) 28291-28299.

[39] S.S. Su, R.S. Lahue, K.G. Au, P. Modrich, Mispair specificity of methyl-directed DNA mismatch correction in vitro, J. Biol. Chem. 263 (1988) 6829-6835. 
[40] S.S. Su, P. Modrich, Escherichia coli mutS-encoded protein binds to mismatched DNA base pairs, Proc. Natl. Acad. Sci. USA 83 (1986) 5057-5061.

[41] M. Viswanathan, V. Burdett, C. Baitinger, P. Modrich, S.T. Lovett, Redundant exonuclease involvement in Escherichia coli methyl-directed mismatch repair, J. Biol. Chem. 276 (2001) 31053-31058.
[42] M.E. Watson Jr., J.L. Burns, A.L. Smith, Hyper mutable Haemophilus influenzae with mutations in mutS are found in cystic fibrosis sputum, Microbiology 150 (2004) 29472958.

[43] K.M. Welsh, A.L. Lu, S. Clark, P. Modrich, Isolation and characterization of the Escherichia coli mut $\mathrm{H}$ gene product, J. Biol. Chem. 262 (1987) 15624-15629. 